\title{
Prevalence and Factors Associated With Episiotomy in Shahroud City, Northeast of Iran
}

\author{
Masoumeh Rasouli ${ }^{1}$, Afsaneh Keramat ${ }^{2^{*}}$, Ahmad Khosravi ${ }^{3}$, Zahra Mohabatpour $^{4}$
}

\begin{abstract}
Objectives: Episiotomy is the most common surgical incision in midwifery. Given its questionable benefits, the present study aimed to determine the frequency of episiotomy and its associated factors in women with vaginal childbirth.

Materials and Methods: This descriptive cross-sectional study was conducted on a population consisting of all women that had vaginal childbirth over a six-month period (from October 2014 to April 2015) in Fatemieh Teaching hospital in Shahroud city. Participants were selected by census. Data were collected using a researcher-made questionnaire consisting of four parts, whose validity and reliability had been confirmed. Data were analyzed in SPSS 21 using descriptive statistics and chi-square, $t$ test and logistic regression analysis.

Results: Of the 978 cases of vaginal childbirth, 406 (41.5\%) had undergone episiotomy. Mean age of participating women was 27.32 \pm 5.14 years. Episiotomy was found to have significant relationships with mother's age, parity, first and fifth minute Apgar scores, duration of the second stage of labor, birth spacing, use of oxytocin, vacuum deliveries and use of analgesics $(P<0.05)$. Overall, prevalence of intact perinea was $34.7 \%$. In the final logistic regression analysis, among significant variables and variables with $\mathrm{P}<0.1$ in univariate analysis, parity, use of oxytocin, first minute Apgar score and infant's head circumference with $P<0.0001$ and birth spacing with $P=0.043$ were considered predictors of episiotomy.

Conclusion: The overall rate of episiotomy in this study was $41.5 \%$, which is much higher than the standards set by the World Health Organization (WHO). Further research is required to provide appropriate solutions to reduce episiotomy.

Keywords: Complications, Epidemiology, Episiotomy, Parturition
\end{abstract}

\section{Introduction}

Episiotomy is the most common incision of perineal muscles in the second stage of labor to widen the vaginal opening (1). The prevalence of episiotomy varies from $9.7 \%$ in Sweden to $100 \%$ in Taiwan (2). In the United States, episiotomy was routinely performed on nearly all primipara until the end of 1970s and declined to $39 \%$ by 1997 (3). In developing countries including Asian ones like India, the prevalence of episiotomy was $90 \%$ (4). In 2009, the prevalence of episiotomy in Iran was reported $88.7 \%$ and 97.3\% in studies by Khani et al in Sari town and Shojae et al in Tehran, respectively $(5,6)$. Various researchers have suggested advantages of episiotomy as follows: avoiding potential intracranial damage to infant, improving Apgar score, avoiding severe and irregular perineal tear, easier restoration of episiotomy incision compared to other incisions, preventing relaxation of pelvic floor muscles and incidence of cystocele and rectocele. However, these advantages have not been supported by solid evidence and with the exception of reduced anterior perineal tear, the rest have not been proven or rejected (3).

A study showed that perineal tear were only observed in women that had not undergone episiotomy, which suggests episiotomy prevents unwanted tear (7). Like other surgical incisions, episiotomy runs the risk of short-term complications such as pain, bleeding and maternal infection and long-term complications such as painful intercourse and complications due to urinary incontinence (8). In a systematic, meta-analysis review study, LaCross et al found a significant relationship between perineal damage due to episiotomy and third or fourth degree tear and postpartum fecal incontinency and emphasized reduction of perineal trauma during vaginal childbirth for reducing fecal incontinency (9). In a study in Turkey, episiotomy was reported responsible for painful intercourse and adverse effects on women's sex life, but not for fecal incontinency (10). A systematic review study by Cochrane library on eight randomized clinical trials on 5000 women revealed that episiotomy should not be routinely performed because it is unnecessary and likely to cause damage. It was also found that routine episiotomy was associated with further loss of blood during childbirth, perineal pain, increased risk of severe perineal tear, needing more stitches and greater complications at wound site and no proven clear benefits for mother or infant (8).

Routine episiotomy is an unnecessary intervention in childbirth, with uncertain benefits. Thus, to reduce unnecessary childbirth interventions, physiological manage- 
ment of childbirth, pleasant labor experience, promotion of maternal and neonatal health and the requirement to practice the 10 measures of mother-friendly hospitals in the country, this study was conducted to determine the prevalence of episiotomy and associated factors in Shahroud city, to find a solution to reduce episiotomy to less than $10 \%$ as recommended by the World Health Organization (WHO).

\section{Materials and Methods}

This descriptive cross-sectional study was conducted to determine the prevalence of episiotomy, associated demographic and obstetrics factors and reasons for episiotomy from the perspective of obstetricians from 7 October 2014 and 6 April 2015. Study population consisted of all pregnant women admitted to Fatemieh Teaching hospital in Shahroud (the only public hospital with maternity ward in city). Participants were selected by census sampling method. After obtaining verbal consent, data were collected from women with vaginal delivery using a four-part researcher-made questionnaire. Part one included demographic and personal details (age, education, nationality, place of residence, occupation, etc.); part two dealt with episiotomy-related obstetric factors (gestational age, parity, infant's head circumference, birth weight, duration of active phase of labor, duration of the second stage of labor, etc.); part three asked about birth method (with or without episiotomy, assisted child birth); and part four assessed midwives details and reasons for episiotomy in their opinion.

Ten senior midwifery students were trained by the researcher on how to complete questionnaires, interview parturient and record data from childbirth files. The presence of one midwifery student was scheduled in every shift to collect the data from admission of parturient to the end of the third stage of labor through interview, observation and delivery records. Validity of questionnaire was ensured using content validity by an opinion survey from nine specialists and faculty members of Shahroud University of Medical Sciences and reliability was determined by comparing data from 20 parturient and childbirth data in official hospital records.

\section{Statistical Analysis}

Data were analyzed in SPSS 21 using descriptive statistics and chi-square, $t$ test, and logistic regression analysis.

\section{Results}

This study was conducted on 978 women that underwent vaginal childbirth in Fatemieh Teaching hospital in Shahroud over six months. Women's mean age was $27.32 \pm 5.14$ years (range: 15 to 44 years). The prevalence of episiotomy was found $41.5 \%$ (406 cases) (Table 1). Among participants, $2.6 \%$ were illiterate, $36.8 \%$ below high school diploma, $45.5 \%$ diploma and $15.1 \%$ had university education. The majority (93.6\%) of participants were housewives, $68.1 \%$ lived in the city and $31.9 \%$ in rural areas and 98.9\% were Iranian. Mean maternal age was 25.79 years in episiotomy group and 28.4 years in non-episiotomy group, with a significant difference between them. No significant relationship was found between episiotomy and place of residence, occupation or race. However, the relationship between episiotomy and mother's education was significant.

Neonatal head circumference was $34.2 \pm 4.16 \mathrm{~cm}$ in episiotomy group and $34.51 \pm 2.42 \mathrm{~cm}$ in non-episiotomy group. No significant relationship was observed between episiotomy and neonatal head circumference $(P=0.146)$, instrumental deliveries $(P=0.401)$, presence of a physician $(P=0.403)$, birth weight $(P=0.935)$ or gestational age $(P=0.173)$ (Table 2). Of the 978 participating women, 572 (58.5\%) had no episiotomy, of whom 339 (59.3\%) had intact perinea, 209 (36.5\%) had first degree tear, 24 (4.2\%) second degree tear and none had third or fourth degree tear. Overall frequency of third degree tear was reported in 3 cases $(0.3 \%)$ and all were in episiotomy group (two cases in primiparous and one in multiparous women). No fourth degree tear was observed. Overall prevalence of intact perinea was $34.7 \%$ (339 women).

Of 978 participants with vaginal childbirth, 431 women (44.06\%) were nulliparous, $372(38.03 \%)$ were with one previous live childbirth, 139 (14.21\%) with two and 36 (3.68\%) with three or more childbirths. Of the 431 nulliparous women 289 (67.1\%), and of women with one childbirth experience $28.5 \%$ and women with two childbirth experiences $7.9 \%$ underwent episiotomy. A significant relationship was found between use of oxytocin to induce and accelerate delivery and episiotomy $(P=0.000)$. Oxy-

Table 1. Frequency of Episiotomy in Women Giving Birth in Fatemieh Teaching Hospital in Shahroud in Terms of Demographic Features

\begin{tabular}{|c|c|c|c|c|c|}
\hline & \multicolumn{4}{|c|}{ Episiotomy } & \multirow{3}{*}{$\mathbf{P}$} \\
\hline & \multicolumn{2}{|c|}{ No } & \multicolumn{2}{|c|}{ Yes } & \\
\hline & Number & $\%$ & Number & $\%$ & \\
\hline Education & & & & & 0.0001 \\
\hline Illiterate & 15 & 60.0 & 10 & 40.0 & \\
\hline Below diploma & 241 & 66.9 & 119 & 33.1 & \\
\hline Diploma & 247 & 55.5 & 198 & 44.5 & \\
\hline University & 69 & 46.6 & 79 & 53.4 & \\
\hline Total & 572 & 58.5 & 406 & 41.5 & \\
\hline Occupation & & & & & 0.5150 \\
\hline Housewife & 539 & 58.9 & 376 & 41.1 & \\
\hline Employee & 30 & 53.6 & 26 & 46.4 & \\
\hline Other & 3 & 42.9 & 4 & 57.1 & \\
\hline Total & 572 & 58.5 & 406 & 41.5 & \\
\hline Place of residence & & & & & 0.2950 \\
\hline Urban & 382 & 57.4 & 284 & 42.6 & \\
\hline Rural & 190 & 60.9 & 122 & 39.1 & \\
\hline Total & 572 & 58.5 & 406 & 41.5 & \\
\hline Race & & & & & 0.4580 \\
\hline Iranian & 565 & 58.4 & 403 & 41.6 & \\
\hline Afghan & 7 & 70.0 & 3 & 30.0 & \\
\hline Total & 572 & 58.5 & 406 & 41.5 & \\
\hline
\end{tabular}


Table 2. Frequency Distribution According to Significantly Related Variable

\begin{tabular}{|c|c|c|c|c|c|}
\hline Variable & Episiotomy & Number & Mean & Standard Deviation & $\boldsymbol{P}$ \\
\hline \multirow{2}{*}{ Maternal age (y) } & No & 572 & 28.40 & 5.10 & \multirow{2}{*}{0.0001} \\
\hline & Yes & 406 & 25.79 & 4.80 & \\
\hline \multirow{2}{*}{ Gravidity } & No & 572 & 2.33 & 1.04 & \multirow{2}{*}{0.0001} \\
\hline & Yes & 406 & 1.42 & 0.68 & \\
\hline \multirow{2}{*}{ Parity } & No & 572 & 1.13 & 0.93 & \multirow{2}{*}{0.0001} \\
\hline & Yes & 406 & 0.32 & 0.52 & \\
\hline \multirow{2}{*}{ Birth spacing (mon) } & No & 550 & 67.76 & 36.46 & \multirow{2}{*}{0.0001} \\
\hline & Yes & 402 & 27.83 & 40.79 & \\
\hline \multirow{2}{*}{ First minute Apgar score } & No & 572 & 8.86 & 1.09 & \multirow{2}{*}{0.0001} \\
\hline & Yes & 406 & 8.21 & 0.77 & \\
\hline \multirow{2}{*}{ Fifth minute Apgar score } & No & 572 & 9.83 & 1.10 & \multirow{2}{*}{0.0001} \\
\hline & Yes & 406 & 9.33 & 0.84 & \\
\hline \multirow{2}{*}{ Second stage of labor (min) } & No & 543 & 32.42 & 22.27 & \multirow{2}{*}{0.0001} \\
\hline & Yes & 406 & 43.25 & 27.58 & \\
\hline \multirow{2}{*}{ Neonatal head circumference } & No & 571 & 34.20 & 4.16 & \multirow{2}{*}{0.146} \\
\hline & Yes & 406 & 34.51 & 2.42 & \\
\hline
\end{tabular}

tocin was administered to 672 out of 978 participants to induce and accelerate natural birth, of whom, 338 women (50.3\%) underwent episiotomy and only $22.3 \%$ of women that had not received exogenous oxytocin during childbirth underwent episiotomy.

A significant relationship was also observed between use of analgesics to relieve labor pain and episiotomy. Of 978 participants, 185 received analgesics for pain relief, of whom, 100 women (54.1\%) underwent episiotomy. Episiotomy was also found significantly related to birth spacing $(P=0.0001)$ and mean spacing between current and previous childbirth was 1.61 years in episiotomy group and 3.27 years in non-episiotomy group (Table 2). In other words, episiotomy reduced with increasing birth spacing. A significant relationship was found between vacuum delivery and increased episiotomy $(P=0.0001)$, so that episiotomy was performed in 11 out of 12 vacuum deliveries.

Among significant variables and those with $\mathrm{P}<0.1$ in univariate analysis, parity $(P<0.0001)$, oxytocin $(\mathrm{P}<0.0001)$, first minute Apgar score $(P<0.0001)$, infant's head circumference $(P<0.0001)$ and birth spacing $(P=0.043)$ were considered predictors of episiotomy. Odds ration (OR) of episiotomy reduced with increasing birth spacing (OR $=0.929,95 \% \mathrm{CI}: 0.866-0.998)$. Odds of episiotomy reduced with increasing parity $(\mathrm{OR}=0.287,95 \% \mathrm{CI}$ : $0.2-0.412$ ), and increased with increasing infant's head circumference (OR $=1.39 ; 95 \% \mathrm{CI}$ : 1.29-1.499), and reduced with increasing first minute Apgar score $(\mathrm{OR}=0.246$; 95\% CI: 0.186-0.324). Administration of oxytocin also increased odds of episiotomy, and episiotomy increased in mothers that had used oxytocin compared to those that had not (OR=2.874; 95\% CI: 1.974-4.182).

In the opinion of midwives, reasons for performing episiotomy included prophylaxis $(58.1 \%)$, short perinea (30\%), fetal distress $(7.6 \%)$, no obvious reason $(2.7 \%)$ and device assisted childbirth (1.5\%) and the most common reasons were prophylaxes and short perinea. Analysis of multiple predictors of episiotomy was performed using forward LR multivariate logistic regression method.

\section{Discussion}

The frequency of episiotomy was found $41.5 \%$. Studies conducted by Khani et al and Shojaee et al in Tehran and Khani in Sari in 2009 reported the prevalence of episiotomy $97.3 \%$ and $88.7 \%$, respectively $(5,6)$. The frequency of episiotomy was significantly less compared to previous studies conducted in Iran, which suggests greater awareness of risks involved according to evidence-based clinical guidelines. As an independent variable, low maternal age was associated with increased episiotomy, such that mean maternal age was 25.79 years in episiotomy group and 28.4 years in non-episiotomy group. In agreement with the present study, a study by Carvalho et al in Brazil showed mean age of mothers 24.7 years in episiotomy group and 24.7 years in non-episiotomy group (11). Other studies have also shown a relationship between younger maternal age and increased risk of episiotomy $(5,12,13)$.

In the present study, logistic regression results confirmed oxytocin as a predictor of episiotomy $(\mathrm{OR}=2.874)$. In separate studies in Brazil by Christianson et al (12) and Braga et al (14), a significant relationship was found between inducing labor with oxytocin and increased frequency of episiotomy, which disagreed with Carvalho et al study (11).

In the present study, birth weight was $3132 \pm 458 \mathrm{~g}$ in episiotomy group and $3135 \pm 537 \mathrm{~g}$ in non-episiotomy group, with no significant difference between them $(P=0.935)$, which is in agreement with Carvalho et al (11) and disagreement with Izuka et al studies (15). In the present study, mean first minute Apgar score was (8.21 \pm 0.77$)$ in episiotomy group and $(8.86 \pm 1.09)$ in non-episiotomy group, with significant difference between them $(P=0.0001)$. In Izuka et al study, $21.7 \%$ of infants in episiotomy group and $15.1 \%$ in non-episiotomy group had 
Apgar scores less than 7, with a significant difference between them (15).

In the present study, during labor, all women were in lithotomy position. Parturient lying in prone position during labor is rooted in midwives' and doctors' comfort rather than in scientific basis (16). Research in Iran shows lithotomy position of mothers in the second stage of labor is associated with an increased episiotomy and perineal trauma while the left lateral position (17) and sitting position (18) reduce the amount of episiotomy. In a systematic review study by Cochrane Library, episiotomy was less performed in upright positions (19).

A positive point in the present study was assessment of the relationship between birth spacing and frequency of episiotomy which had not been investigated in other studies. Hence, appropriate birth spacing can probably reduce episiotomy, which is hoped to be further studied in future. In our study and the study of Khani (20) in Sari (northern Iran) all cases of severe perineal tears in episiotomy were observed. In this study prophylaxis and prevention of severe perineal tear were mentioned as the most common reasons for episiotomy; consultations with delivery agents as well as increasing their skills are recommended.

In this study, the majority of mothers used Valsalva maneuver for pushing in the second stage of labor. Studies in Iran have shown pushing with breathing techniques instead of Valsalva maneuvers is one of the effective solutions to reduce episiotomy (21-23). Therefore, it is necessary to reduce unnecessary interventions during labor and further research is required to provide appropriate solutions to reduce episiotomy.

Considering that according to the WHO episiotomy should be performed in less than $10 \%$ of cases of natural births (24), hence, mothers' knowledge should be raised about the adverse consequences of unnecessary episiotomy in order to reduce its prevalence. Policy to limit episiotomy can also be effective (8).

\section{Conclusion}

It is hoped that the results obtained can affect favorable changes in midwifery processes in Iran. Increasing midwives' skills, performing episiotomy only according to scientific indications and in limited cases, reduce unnecessary interventions during labor, providing women with information about childbirth methods in preparation classes are recommended. Further research is required to provide appropriate solutions to reduce episiotomy.

\section{Ethical Issues}

The project was approved on June 19, 2014 with the proposal code of 9310 and ethics code of IR.SHMU. REC.1394.19 at Shahroud University of Medical Sciences.

\section{Conflict of Interests}

None.

\section{Financial Support}

This study was supported by the Shahroud University of
Medical Sciences, Shahroud, Iran.

\section{Acknowledgments}

None to be declared.

\section{References}

1. Jovanovic NS, Kocijancic DM, Terzic MM. Current approach to episiotomy: Inevitable or unnecessary?. Central European J Med. 2011;6(6):685-690. doi:10.2478/ s11536-011-0088-z.

2. Graham ID, Carroli G, Davies C, Medves JM. Episiotomy rates around the world: an update. Birth. 2005;32(3):219223. doi:10.1111/j.0730-7659.2005.00373.x.

3. Cunningham FG, Leveno KJ, Bloom SL, et al, eds. Williams Obstetrics. 23rd ed. New York, NY; McGraw-Hill; 2010.

4. Kropp N, Hartwell T, Althabe F. Episiotomy rates from eleven developing countries. Int J Gynaecol Obstet 2005;91(2):157-159. doi:10.1016/j.ijgo.2005.07.013.

5. Khani S, Zare K, Ramezannezhad SE. The frequency of episiotomy and its related factors. Iran $\mathrm{J}$ Nurs. 2012;24(74):45-52.

6. Shojae KK, Dawati A, Zayeri F. Frequency and side effect of episiotomy in primiparous women: a three-month longitudinal survey. Qom Univ Med Sci J. 2009;3(2):47-50.

7. Ekwempu CC. Maternal injuries. In: Agboola A, ed. Textbook of Obstetrics and Gynaecology for Medical Students. Ibadan: Heinemann Educational Book Plc; 2006:477- 80.

8. Carroli G, Mignini L. Episiotomy for vaginal birth. Cochrane Database Syst Rev. 2009;(1):CD000081. doi: 10.1002/14651858.CD000081.pub2.

9. LaCross A, Groff M, Smaldone A. Obstetric anal sphincter injury and anal incontinence following vaginal birth: a systematic review and meta-analysis. J Midwifery Womens Health. 2015;60(1):37-47. doi:10.1111/jmwh.12283.

10. Boran SU, Cengiz H, Erman O, Erkaya S. Episiotomy and the development of postpartum dyspareunia and anal incontinence in nulliparous females. Eurasian J Med. 2013;45(3):176-180. doi:10.5152/eajm.2013.36.

11. Carvalho CC, Souza AS, Moraes Filho OB. Prevalence and factors associated with practice of episiotomy at a maternity school in Recife, Pernambuco, Brazil (Portuguese). Revista da Associacao Medica Brasileira. 2010;56(3):333-9. doi:10.1590/S0104-42302010000300020.

12. Christianson LM, Bovbjerg VE, McDavitt EC, Hullfish KL. Risk factors for perineal injury during delivery. Am J Obstet Gynecol. 2003;189(1):255-260. doi:10.1067/mob.2003.547.

13. Escuriet R, Pueyo MJ, Perez-Botella M, et al. Crosssectional study comparing public and private hospitals in Catalonia: Is the practice of routine episiotomy changing? BMC Health Serv Res. 2015;15:95. doi:10.1186/s12913015-0753-z.

14. Braga GC, Clementino ST, Luz PF, Scavuzzi A, Noronha Neto C, Amorim MM. Risk factors for episiotomy: a casecontrol study. Revista da Associação Médica Brasileira. 2014;60(5):465-72. doi:10.1590/1806-9282.60.05.015.

15. Izuka E, Dim C, Chigbu C, Obiora-Izuka C. Prevalence and predictors of episiotomy among women at first birth in enugu, South-East Nigeria. Ann Med Health Sci Res. 2014;4(6):928-932. doi:10.4103/2141-9248.144916.

16. Hueston WJ. Factors associated with the use of episiotomy during vaginal delivery. Obstet Gynecol. 1996;87(6):10011005 . 
17. Golmakany A, Mehran F, Mazloom S. Effects of left lateral position compared with lithotomy position in the second stage of labour on nulliparous women perineal trauma. J Mazandaran Univ Med Sci. 2005;15(49):57-64.

18. Sekhavat L, Karimzadah Mibodi M. Effect of maternal position on duration of second stage of labor and maternal and neonatal out come in nulliparous women. J Gorgan Univ Med Sci. 2009;11(2):33-37.

19. Gupta JK, Hofmeyr GJ, Shehmar M. Position in the second stage of labour for women without epidural anaesthesia. Cochrane Database Syst Rev. 2012;(5):CD002006. doi: 10.1002/14651858.CD002006.
20. Khani S, Shaebankani B. Episiotomy: A preventive medication of extensive genital tract trauma or a risk factor. Modraes J Med Sci. 2001;4(1): 9-16.

21. Motevasselian M, Farnia F. Effect of relaxation on episiotomy incisional pain. J Yazd Univ Med Sci. 2002;10(3):25-31.

22. Asali R. Effect of pushing on second stage of labour on perineal trauma. Obstet Gynacol Infertil J. 2009;2(8):43-48.

23. Ahmadi $Z$. Review of effective methods to reduce damage to the perineum during delivery and its recovery. Iran J Obstet Gynecol Infertil. 2015;18(155):19-30.

24. World Health Organization. Care in normal birth: a practical guide. Geneva: WHO; 1996.

Copyright (c) 2016 The Author(s); This is an open-access article distributed under the terms of the Creative Commons Attribution License (http://creativecommons.org/licenses/by/4.0), which permits unrestricted use, distribution, and reproduction in any medium, provided the original work is properly cited. 